This item was submitted to Loughborough's Research Repository by the author.

Items in Figshare are protected by copyright, with all rights reserved, unless otherwise indicated.

\title{
Low-power microwave plasma source based on a microstrip split-ring
}

\section{resonator}

PLEASE CITE THE PUBLISHED VERSION

PUBLISHER

(c) IEEE

LICENCE

CC BY-NC-ND 4.0

REPOSITORY RECORD

Iza, Felipe, and Jeffrey A. Hopwood. 2019. "Low-power Microwave Plasma Source Based on a Microstrip Split-ring Resonator". figshare. https://hdl.handle.net/2134/3211. 
This item was submitted to Loughborough's Institutional Repository by the author and is made available under the following Creative Commons Licence conditions.

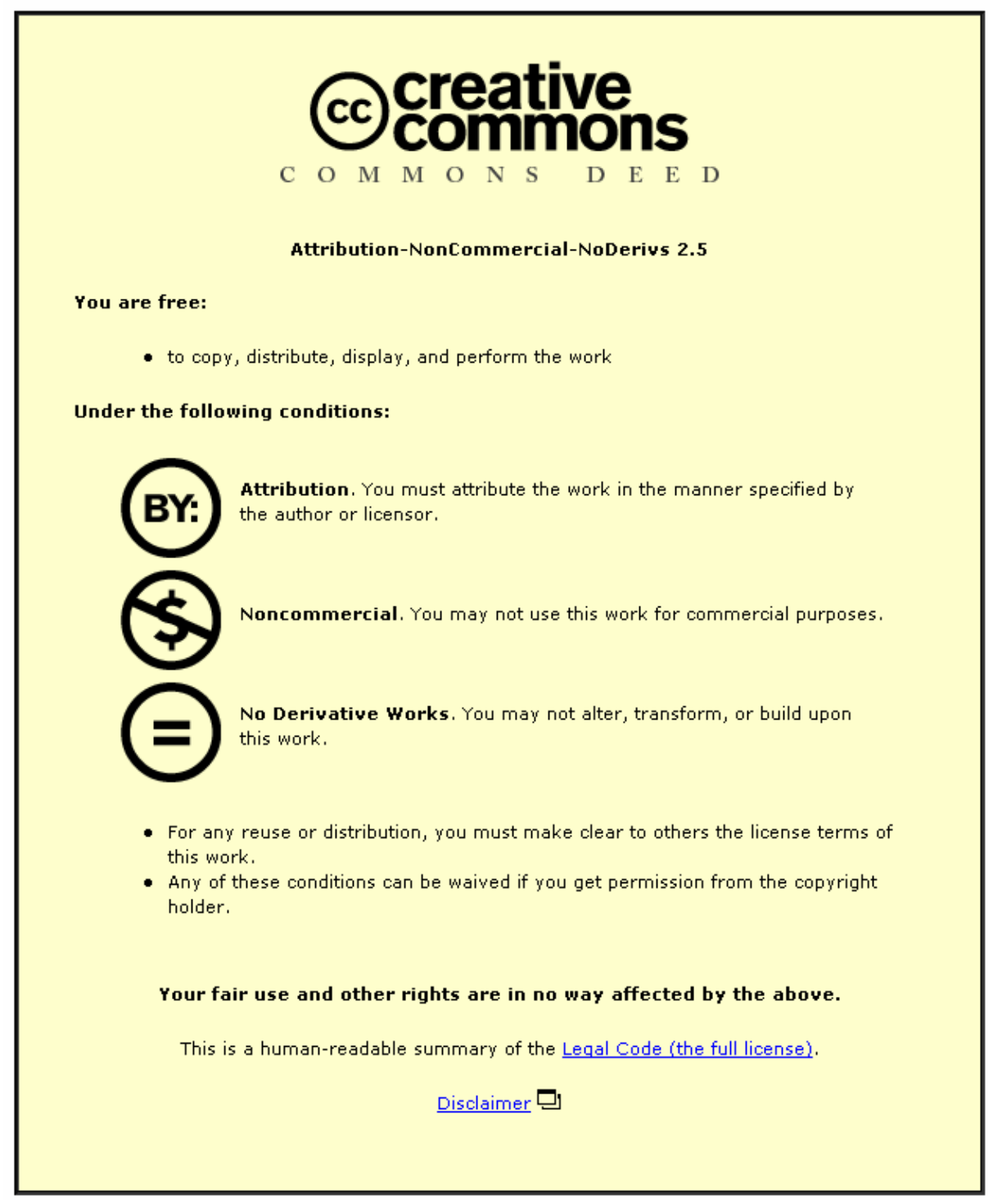

For the full text of this licence, please go to: http://creativecommons.org/licenses/by-nc-nd/2.5/ 


\title{
Low-Power Microwave Plasma Source Based on a Microstrip Split-Ring Resonator
}

\author{
Felipe Iza, Student Member, IEEE, and Jeffrey A. Hopwood, Member, IEEE
}

\begin{abstract}
Microplasma sources can be integrated into portable devices for applications such as bio-microelectromechanical system sterilization, small-scale materials processing, and microchemical analysis systems. Portable operation, however, limits the amount of power and vacuum levels that can be employed in the plasma source. This paper describes the design and initial characterization of a low-power microwave plasma source based on a microstrip split-ring resonator that is capable of operating at pressures from 0.05 torr $(6.7 \mathrm{~Pa})$ up to one atmosphere. The plasma source's microstrip resonator operates at $900 \mathrm{MHz}$ and presents a quality factor of $\mathrm{Q}=335$. Argon and air discharges can be self-started with less than $3 \mathrm{~W}$ in a relatively wide pressure range. An ion density of $1.3 \times 10^{11} \mathrm{~cm}^{-3}$ in argon at $400 \mathrm{mtorr}$ (53.3 Pa) can be created using only $0.5 \mathrm{~W}$. Atmospheric discharges can be sustained with $0.5 \mathrm{~W}$ in argon. This low power allows for portable air-cooled operation. Continuous operation at atmospheric pressure for $24 \mathrm{~h}$ in argon at $1 \mathrm{~W}$ shows no measurable damage to the source.
\end{abstract}

Index Terms-Low-power microplasma, microwave plasma, split-ring resonator.

\section{INTRODUCTION}

$\mathbf{T}$ HE COMPLEXITY of microelectromechanical systems (MEMS) and the scope of their applications have broadened in the last decade. In recent years, an effort to fabricate microplasma sources that can be integrated with other MEMS devices to form larger microsystems has been made. Plasma-based microsystems can find application in bio-MEMS sterilization, small-scale materials processing, and microchemical analysis systems. However, integrability requires not only a reduction in size, but also an understanding of the physics governing the new small-scale discharges. At the same time, portable microsystems impose new constraints on the amount of power and the vacuum levels that can be employed. Operation at atmospheric pressure is particularly interesting for microplasma sources as it eliminates the need for vacuum pumps. Micropumps increase the final cost of the system, are inefficient in achieving high vacuum levels, and may reduce the overall system reliability.

In recent years, a variety of microplasma sources with potential use in different portable devices have been reported. DC plasma sources operating in $\mathrm{He}$ at $100-760$ torr (13.3$101.3 \mathrm{kPa}$ ) have been used for optical emission detection [1], [2] and localized micromachining of silicon [3]. DC sources

\footnotetext{
Manuscript received February 4, 2003; revised April 5, 2003. This work was supported by the National Science Foundation under Grant DMI-0078406, and by the Fulbright Program.

The authors are with the Department of Electrical and Computer Engineering, Northeastern University, Boston, MA 02115 USA (e-mail: hopwood@ ece.neu.edu)

Digital Object Identifier 10.1109/TPS.2003.815470
}

present a limited lifetime due to sputter erosion of the electrodes. This erosion of microelectrodes has also been exploited, however, to create a dc glow discharge using microfabricated liquid electrodes [4] for the spectroscopic detection of metals. Microhollow cathodes, operating at $\sim 300-\mathrm{V}$ dc, have been fabricated to create plasma curtains at atmospheric pressure [5] and as sources of UV light [6]. Dielectric barrier discharges have also been miniaturized and used for gas analysis [7]. RF discharges, particularly inductively coupled plasma sources, present longer lifetimes than dc discharges. Microplasma sources operating in the capacitively coupled mode [8], [9] and the inductively coupled mode [10] have been reported. Microwave plasma sources have also been miniaturized. Although they may not be reduced in size as much as other devices, microwave plasma sources present the advantage of simplicity, robustness, and longer lifetime than most of the other approaches. Microplasma sources based on linear microstrip resonators have been recently reported [11], [12].

This paper presents the design and characterization of a low-power microwave microplasma source based on a microstrip split-ring resonator. The device requires less than $3 \mathrm{~W}$ at $900 \mathrm{MHz}$ to self-start argon and air discharges in a relatively wide pressure range. The high-quality factor of the resonator allows the source to self-start the discharge and to efficiently sustain the plasma up to atmospheric pressure. The energy of the ions impacting against the microstrip is very low due to the collisional nature of the sheath and the low sheath potential at pressures above 1 torr (133.3 Pa). As a result, continuous operation in argon at atmospheric pressure for $24 \mathrm{~h}$ shows no significant damage to the device.

\section{SOURCE DESIGN}

The plasma source consists of a microstrip structure, as shown in Fig. 1. The plasma is generated in the small gap of a split-ring resonator. A quarter wavelength transformer is used to match the impedance of the ring to that of the power supply. The ring resonator is only a half wavelength in circumference, instead of one full wavelength of other linear microwave designs [11], [12]. Given the ring geometry and the high dielectric constant of the substrate used $\left(\varepsilon_{r}=10.8\right)$, a compact design suitable for portable systems is obtained. The key feature of this design is that the electric field concentrates in the gap. Since the voltage at each end of the ring is $180^{\circ}$ out of phase, the maximum voltage difference in the device occurs right across the gap where the discharge is to be ignited.

Fig. 2 shows a top view and two cross-sections of the magnitude of the electric field pattern in the split-ring resonator computed using the High Frequency Structure Simulator (HFSS) from Ansoft Corporation. It can be seen that the electric field is 


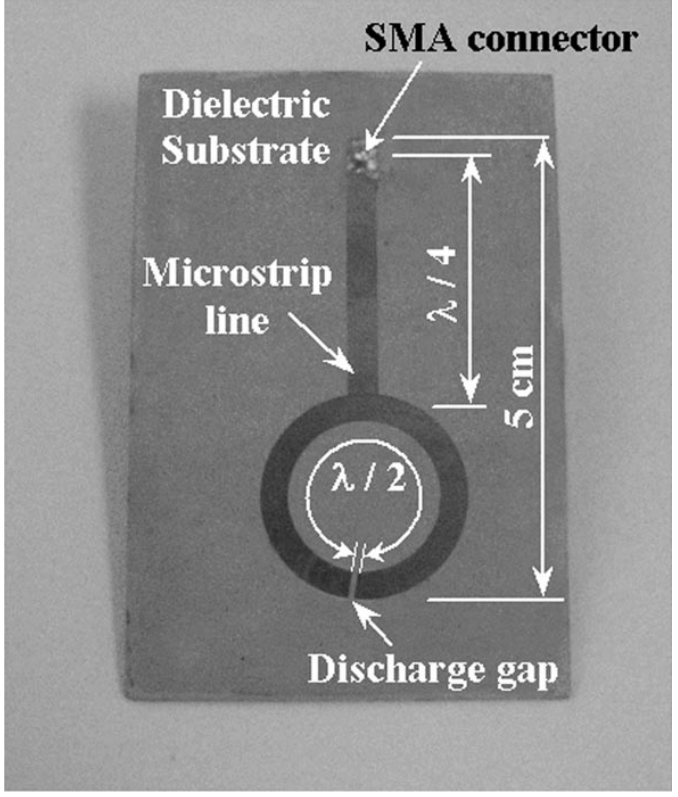

Fig. 1. Photograph of the top view of the microstrip structure

confined around the microstrip lines thereby exhibiting low radiation losses. The confinement of the electric field also reduces interference with other electronic equipment. The electric field pattern along most of the ring is that of a typical microstrip line (section $\mathrm{AA}^{\prime}$ ), i.e., $E$ is concentrated between the line and the ground plane with fringing fields at the edges.

Near the gap, however, the electric fields at each end of the ring interact with each other (section BB'). Instead of going from the line to the ground plane, they cross directly from one end of the ring to the other. Not only does the electric field in the gap change direction, but it also changes in magnitude. Since the ends of the ring are $180^{\circ}$ out of phase, the electric field in the gap doubles in magnitude compared to that in the microstrip line. This characteristic favors discharge breakdown in the gap while minimizing losses in the rest of the device. Moreover, by reducing the gap length with respect to the dielectric thickness, further amplification of the field can be achieved. Reducing the gap, however, increases the capacitive coupling between the two ends of the resonator. This needs to be taken into account in the design process as it shifts the resonant frequency of the structure.

The device was designed using analytical equations based on the quasi-static approximation [13], [14] and then refined by finite-element analysis. It was fabricated on RT/Duroid 6010.8 laminate, which consists of a $635-\mu \mathrm{m}$-thick dielectric coated with $9-\mu \mathrm{m}$-thick copper on both sides. The dielectric material is made out of ceramic-reinforced teflon with a relative dielectric constant of 10.8. The microstrip pattern is transferred using photolithography and wet etching techniques, and a subminiature type-A (SMA) connector is attached perpendicular to the microstrip line to deliver power to the plasma generator.

The actual device closely matches the simulation results in terms of frequency of operation, quality factor, and input impedance. Fig. 3 shows the reflection coefficient $\left(\mathrm{s}_{11}\right)$ of the device (including the SMA connector) measured with a HP8714ET network analyzer. From the reflection coefficient, the quality factor of the device can be obtained as

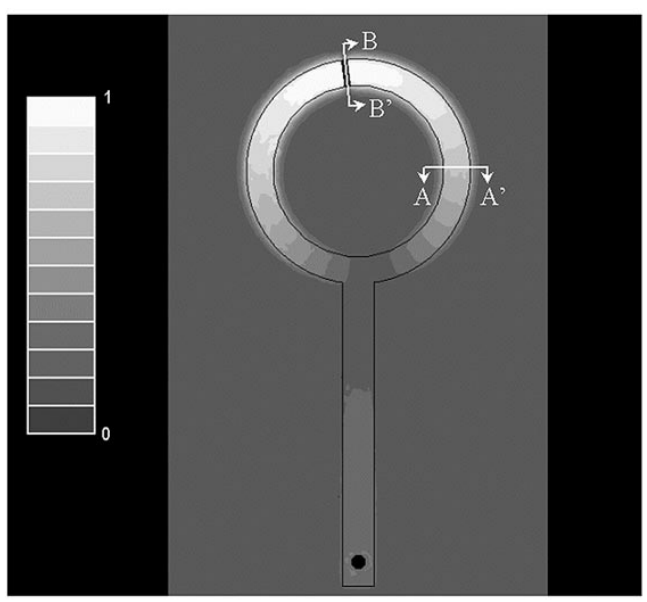

(a)

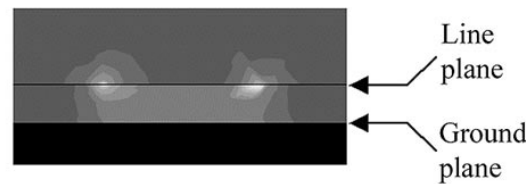

(b)

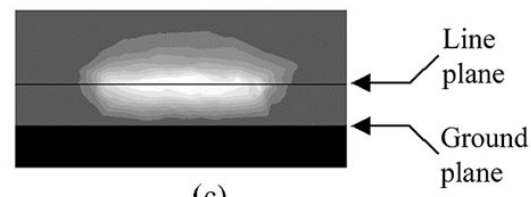

(c)

Fig. 2. Finite-element analysis using HFSS. (a) Magnitude of the electric field in a plane $250 \mu \mathrm{m}$ above the ground plane (dielectric thickness $=650 \mu \mathrm{m}$ ). (b) Section AA': Magnitude of the electric field in a plane perpendicular to the ground plane. (c) Section BB': Magnitude of the electric field in a plane perpendicular to the ground plane through the discharge gap.

$Q=f_{c} / \Delta f_{3 d B}$, where $f_{c}$ is the resonant frequency and $\Delta f_{3} d B$ the bandwidth where the reflection coefficient increases by $3 \mathrm{~dB}$ from its value at resonance [15]. From Fig. 3, the quality factor of the actual device is $\sim 335$.

Quality factors of hundreds are typical in microstrip circuits. It should be noticed, however, that previous microfabricated inductively coupled plasma sources operating in this range of frequencies presented poorer quality factors on the order of 40 [16] Therefore, better power efficiency should be expected for this device. The fact that a plasma can be self-ignited without the help of a spark corroborates this observation.

\section{EXPERIMENT}

\section{A. Experimental Setup}

Once the device has been fabricated and the SMA connector bonded, it is attached to a glass tube that acts as vacuum chamber. The glass tube is bonded with epoxy and a photoresist coating has been used as an intermediate layer between the epoxy and the device so that the tube can be easily detached from the device after operation. The glass tube is terminated in a metal flange that attaches the tube to a vacuum manifold (see Fig. 4). Access to the vacuum chamber for probe measurements is gained through this manifold.

The gases used for the experiments are high purity argon and room air. These are metered through the gas inlet, and a me- 

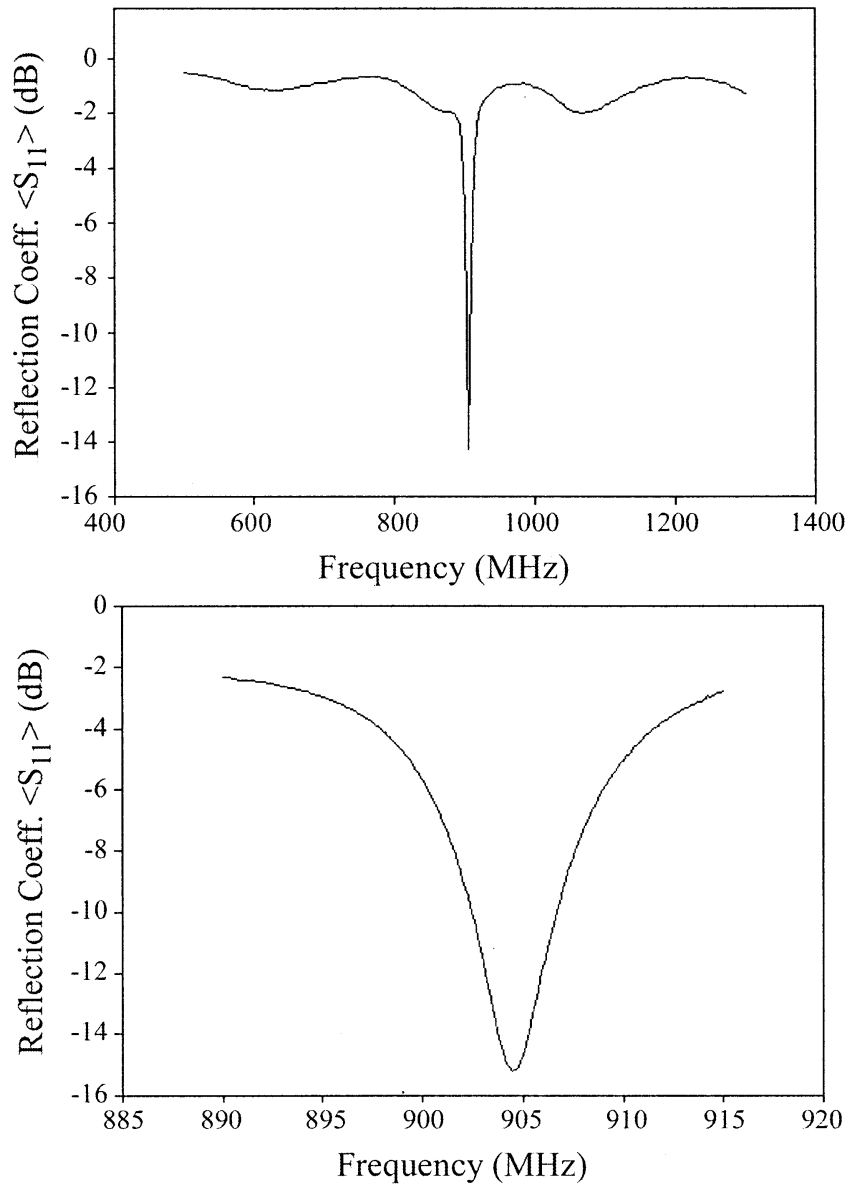

Fig. 3. Reflection coefficient $\left(\mathrm{s}_{11}\right)$ measured with a HP8714ET network analyzer.

chanical pump is used to create vacuum in the chamber when needed. A capacitance manometer measures the pressure in the chamber and a needle valve at the inlet allows us to vary the pressure by altering the gas flow. For pressures higher than 10 torr $(1.33 \mathrm{kPa})$, a convectron pressure gauge is used.

A signal generator (HP8656A) and a 3-W linear RF amplifier (ENI603L) are used to supply power to the plasma source. At times, an amplifier chip for wireless communications (Celeritek CHP0230-PM) has also been used to supply power to the plasma. A dual-directional coupler, an RF switch, and an $\mathrm{RF}$ power meter are used to measure the forward and reflected power. In this work, the plasma power is reported as the difference between the forward and reflected power.

\section{B. Experiment Description}

The discharge at low pressure is diagnosed using an asymmetric double Langmuir probe scheme [17]. Due to the small dimensions of the plasma, careful attention needs to be paid to the probe selection. The probe used is a coaxial cable in which the inner conductor $(0.20-\mathrm{mm}$ diameter, $1 \mathrm{~mm}$ long $)$ acts as one of the probes and the outer conductor $(0.86-\mathrm{mm}$ diameter) serves as the second probe. The experiment conditions, i.e., gas type, pressure range, and chamber size, and the algorithm used to determine the electron temperature and the ion density are identical to those in [16] where a microfabricated inductively coupled plasma (ICP) source was tested. Therefore, a direct and

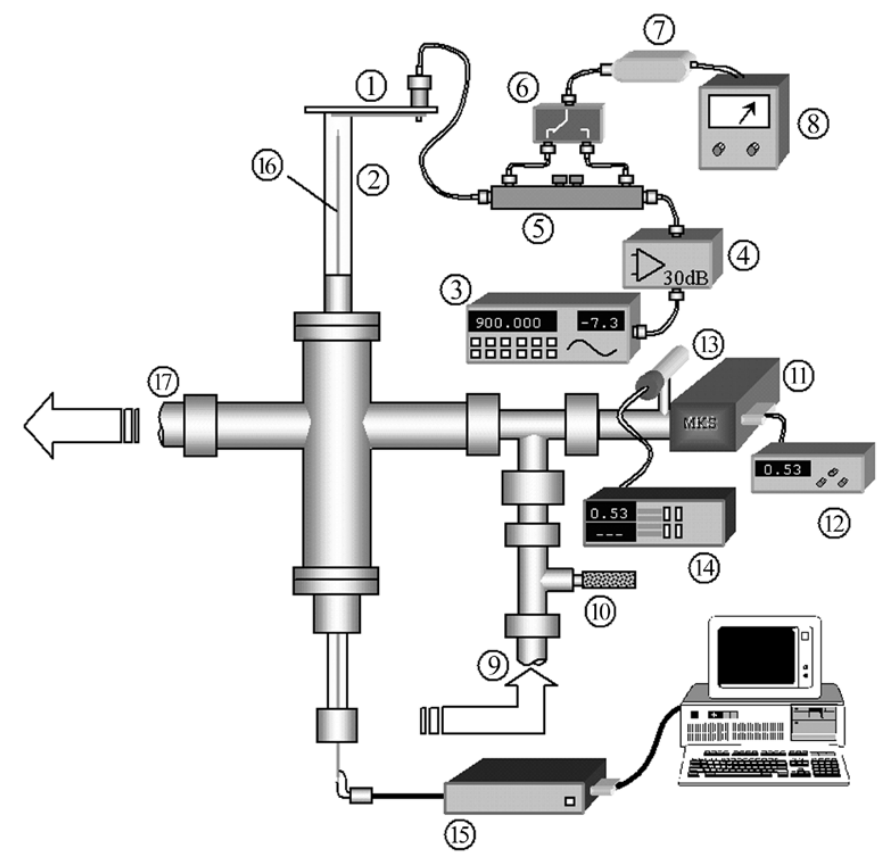

Fig. 4. Setup schematic. (1) Microwave plasma source. (2) An 8-mm glass tube (vacuum chamber). (3) Signal generator (HP 8656A). (4) RF power amplifier (ENI 603L). (5) RF coupler (Pasternack PE2217-20). (6) RF switch. (7) RF power sensor (HP 8482H). (8) RF power meter (HP 435A). (9) Gas inlet (argon/air). (10) Needle valve (Cajon SS4). (11) Capacitive pressure gauge (MKS 390HA-10 torr). (12) Signal conditioner (MKS 270B). (13) Series 275 convectron gauge (1000 torr). (14) Vacuum gauge controller (Granville-Phillips 307). (15) Electrostatic plasma probe controller (Hiden ESP004). (16) Coaxial Langmuir probe (17) Gas outlet (to pump).

fair comparison between this microwave plasma source and a microfabricated ICP source can be carried out.

The Langmuir probe measurement can only be carried out at low pressures since it is based on the assumption of collisionless sheaths. For this reason, only measurements up to $400 \mathrm{mtorr}$ (53.3 Pa) are reported. Although collisional probe theory can be applied at higher pressures, the microplasma dimensions makes these measurements unreliable, as it is impossible to immerse both conductors of the coaxial probe in the plasma without perturbing it. During this experiment, a polymer coating was applied over the microstrip structure to isolate the source from the plasma. This is the same procedure used in the ICP source experiments described in [16]. This phase of the experiment is carried out only in argon, as air plasma would etch the isolating polymer coating.

To gain some insight into the energy with which ions impact against the microstrip, the isolating polymer was stripped and the floating potential in argon was measured for pressures up to one atmosphere. A thin gold wire $(\sim 50 \mu \mathrm{m})$ placed along the center of the discharge gap was employed as a probe for measuring the floating potential. Placing the wire in this way guarantees contact between the probe and the plasma even at high pressures, when the discharge becomes confined within the 500- $\mu \mathrm{m}$-wide gap region. Since the dc potential of the microstrip is grounded by the power supply, the sheath potential at the microstrip is given by the plasma potential, which is pinned by the peak RF voltage applied to each end of the microstrip. Therefore, the average sheath potential at the microstrip may be 


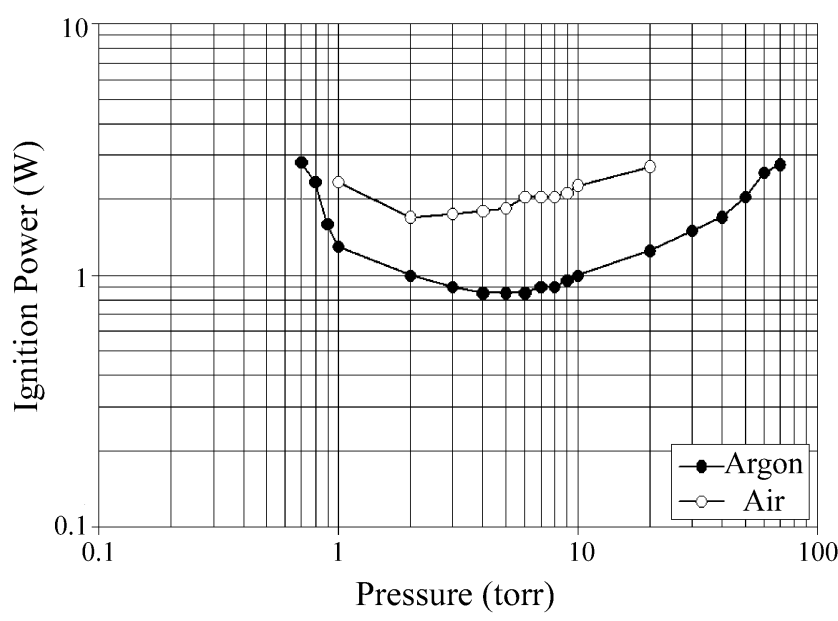

(a)

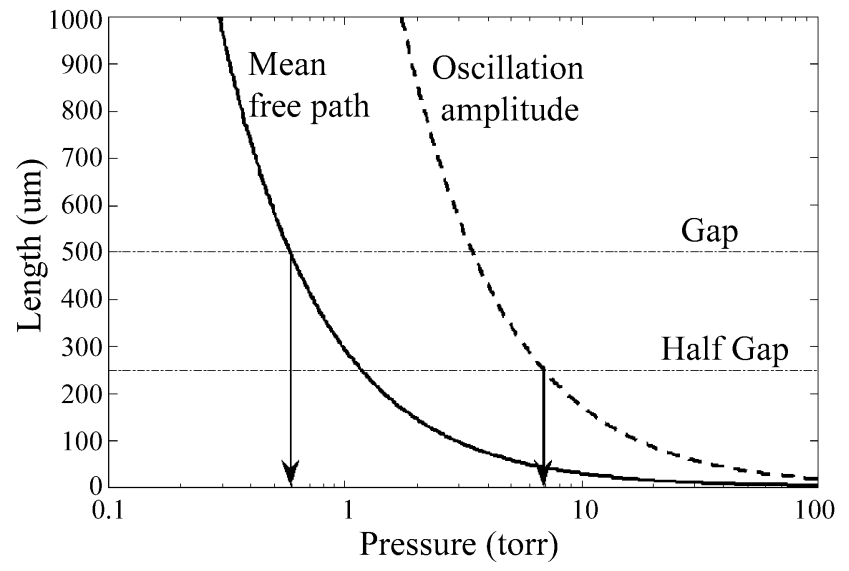

(b)

Fig. 5. (a) Ignition power versus pressure for Ar and air. (b) Electron mean-free path (solid) and electron oscillation amplitude (dashed) versus pressure.

determined as the floating potential plus the sheath voltage at a floating surface $\left(\sim 5 \mathrm{~T}_{\mathrm{e}}\right.$ for argon at low pressure [18]).

\section{RESULTS AND DisCUSSION}

\section{A. Ignition Power}

Fig. 5(a) shows the ignition power versus pressure for argon and air discharges. The power available was limited to $3 \mathrm{~W}$ by the power amplifier and the accuracy of the measurements is $\pm 0.1 \mathrm{~W}$. As expected, higher power is needed to start a discharge in air due to the molecular nature of this gas. A discharge in argon can be ignited with only $850 \mathrm{~mW}$ at 5 torr $(666.6 \mathrm{~Pa})$ whereas $1.7 \mathrm{~W}$ is needed to ignite an air discharge at 2 torr $(266.6 \mathrm{~Pa})$. The physical origins of breakdown in the gap are explored next.

The high-pressure part of the curves in Fig. 5(a) corresponds to a diffusion limited region in which breakdown occurs when ionization of the gas equals the electron loss due to diffusion. In this region, both the electron mean-free path and the amplitude of the oscillation of the electrons due to the sinusoidal excitation are smaller than the gap [see Fig. 5(b)]. Thus, electrons are more or less trapped in the gap, colliding with the gas molecules and ionizing them. The dominant loss of electrons is due to diffusion, rather than field-induced drift. A lowering of pressure in this region moves one toward the condition $\nu=\omega$, where $\nu$ is the electron-neutral collision frequency. Specifically, lower pressure increases the mean-free path of the electrons and,therefore, lower power is needed to accelerate electrons to the ionization energy between collisions.

As the pressure drops to $\sim 7$ torr $(933.1 \mathrm{~Pa})$, however, the oscillation amplitude of the electrons increases up to a point where it becomes comparable to the gap length. When the amplitude of the oscillation is greater than half the gap, electron loss at the electrodes due to drift dominates over diffusion processes. A minimum ignition power is reached near 5 torr $(666.5 \mathrm{~Pa})$ in Ar and 2 torr $(266.6 \mathrm{~Pa})$ in air, and a further decrease in pressure makes the loss of electrons to the electrodes larger. It is important to note that the narrow gap spacing $(\sim 500 \mu \mathrm{m})$ causes the minimum ignition pressure to be higher than classically predicted by $\nu=\omega$.

At sufficiently low pressure $(<0.7$ torr $(93.3 \mathrm{~Pa})$ in Ar), both the oscillation amplitude of the electrons and the mean-free path exceed the gap length. At this point, the electrons transit the gap without colliding with the gas molecules, and are lost at the electrodes. Therefore, the plasma cannot be ignited and an abrupt increase in ignition power is observed (left part of the curves).

Fig. 5(b) shows the estimated electron mean-free path and the amplitude of the oscillation in argon as a function of pressure. An electron temperature of $2 \mathrm{eV}$, a collision rate of $10^{-13} \mathrm{~m}^{3} / \mathrm{s}$ [19], and an applied-peak voltage across the gap of $90 \mathrm{~V}$ (based on simulations) have been assumed. The arrows correspond to the conditions where a change in the mechanism of breakdown is expected, i.e., the electron oscillation amplitude equals half the gap and the electron mean-free path equals the gap. This prediction is in agreement with the experimental results for argon [Fig. 5(a)].

\section{B. Visual Description of the Plasma}

Once the plasma is self-started at low pressure, it can be run in a wide pressure range, i.e., from 50 mtorr $(6.67 \mathrm{~Pa})$ up to atmospheric pressure. Fig. 6 shows an Ar discharge at three different pressures running at $1 \mathrm{~W}$. Given the brightness of the discharge at high pressure, the device cannot be seen in the pictures, therefore, the microstrip and the glass chamber have been drawn for clarity. At low pressure, the plasma expands out of the gap creating a relatively large volume of plasma $\left(\sim 0.5 \mathrm{~cm}^{3}\right)$. As the pressure increases, however, the mean-free path of the particles decreases and the plasma becomes confined closer to the gap where the electrons are being heated. At 20 torr $(2.67 \mathrm{kPa})$, it is possible to see the microstrip lines through the discharge. Further increases in pressure confine the plasma to the gap region up to a point where it acquires a shape similar to that of a filament [Fig. 6(c)].

Filaments are typically associated with arcs, which implies a thermal process in which electrodes become hot so that the onset of thermionic emission increases the intensity of the discharge. The high temperature achieved in arcs is evidenced by the damage induced to their electrodes. In our case, however, the fact that the source has been continuously operated for more than $24 \mathrm{~h}$ at atmospheric pressure, without indications of erosion in the copper microstrip lines, leads us to conclude that the discharge is not in thermal equilibrium. At $1 \mathrm{~atm}, \mathrm{~T}_{\text {gas }}$ is much less than $\mathrm{T}_{\mathrm{e}}$, and, therefore, the microstrip resonator does not generate a true arc. 


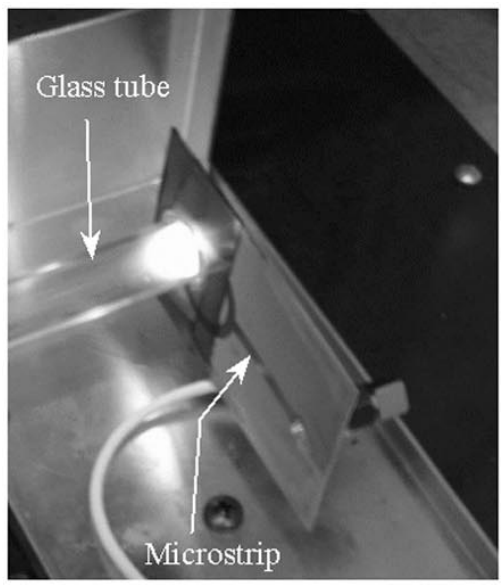

(a)

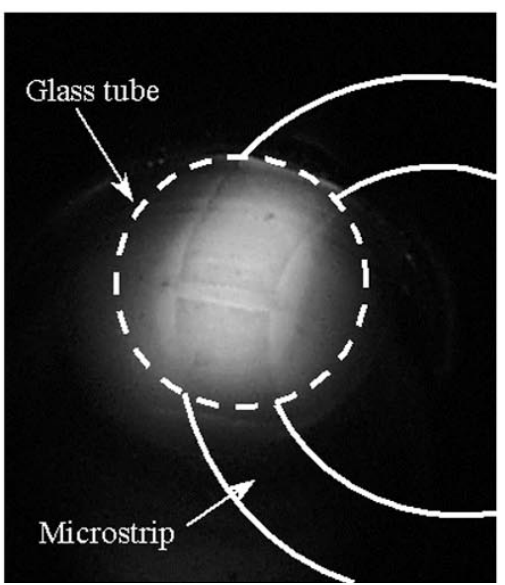

(b)

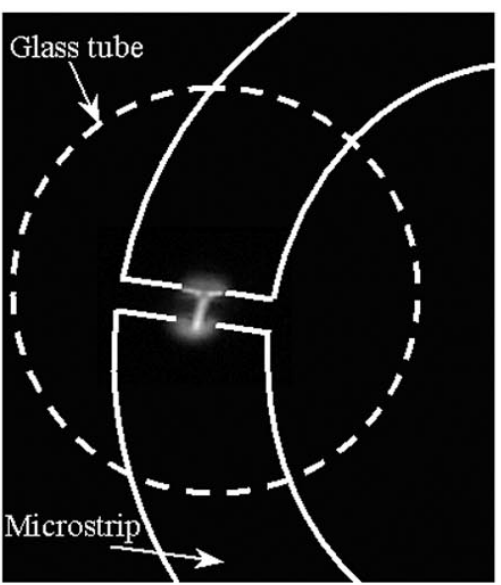

(c)

Fig. 6. Ar plasma at $1 \mathrm{~W}$. (a) View of the device operating at 9 torr $(1.2 \mathrm{kPa}$ ). (b) Close-up view of the diffuse plasma at 20 torr $(2.67 \mathrm{kPa})$. (c) Close-up view of the confined plasma at 760 torr $(101.3 \mathrm{kPa})$

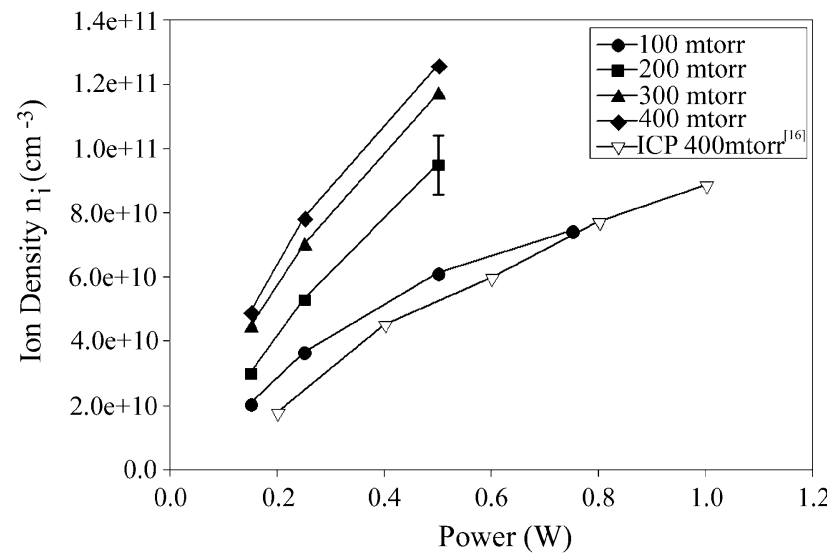

Fig. 7. Ion density in an argon discharge versus absorbed power with a typical error bar shown. The result of an ICP under the same conditions has been added for comparison [16].

\section{Ion Density}

The high-quality factor of the split-ring resonator not only allows for self-starting the discharge with a small amount of power, but also accounts for high-efficiency operation. The ion density per watt absorbed by the plasma is an indicator of the efficiency of the device. Fig. 7 shows the ion density as a function of power and pressure for the microwave plasma source operating at $900 \mathrm{MHz}$. The ion density obtained with an ICP under similar conditions (same gas, pressure, chamber size, and diagnostic technique) [16] has been added to the plot for comparison. The microwave plasma source creates an ion density of $1.3 \times 10^{11} \mathrm{~cm}^{-3}$ at $400 \mathrm{mtorr}(53.3 \mathrm{~Pa}$ ) while consuming only $0.5 \mathrm{~W}$. This corresponds to an increase in ion density of $\sim 250 \%$ with respect to the microfabricated ICP source. The high ion density is attributed to low sheath potentials, and very low ohmic and radiative power losses in the microstrip lines.

\section{Floating Potential}

As mentioned in Section III-B, the discharge is not in thermal equilibrium even at atmospheric pressure. Moreover, the microstrips are not sputtered at any significant rate, which suggests that the ions bombarding the microstrip have low energy.

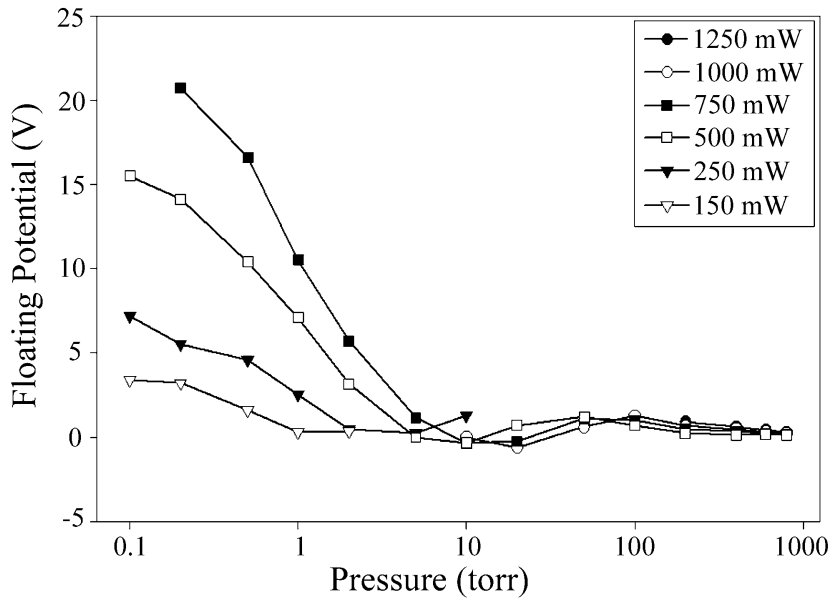

Fig. 8. Floating potential in argon discharge versus pressure.

This observation agrees with the floating potential measurements shown in Fig. 8. A floating potential of a few volts is observed for pressures higher than $\sim 1$ torr $(133.3 \mathrm{~Pa})$, and, therefore, the sheath voltage at the microstrips can be estimated to be on the order of $\sim 15 \mathrm{~V}$ in this pressure range. The collisional nature of the sheath and the low sheath potential for pressures above 1 torr (133.3 Pa), explains why sputtering is not observed.

In the low-pressure region [below $\sim 5$ torr $(666.6 \mathrm{~Pa})]$, the floating potential increases with input power and decreasing pressure. This behavior resembles that of a capacitively coupled plasma source in which an increase in input power or a decrease in pressure increases the sheath voltage at the driven electrodes [20]. The increased sheath voltage manifests itself as a higher floating potential. This microwave plasma source presents a similar structure to that of a capacitively coupled plasma source, i.e., two electrodes (two ends of a microstrip in this case) with an applied field that is perpendicular to them, and, therefore, it is not surprising to observe a similar behavior. The very high frequency of operation, however, reduces the impedance of the sheath and the sheath voltage, and, therefore, reduces the energy lost in accelerating ions in the sheath. This increases the overall efficiency of the device and at the same time reduces the damage to the electrodes. 
At high pressure, however, no significant power or pressure dependence is observed in the floating potential. This indicates that the sheath voltage around the microstrips is independent of the input power and therefore, any variation in the voltage across the gap as the input power is varied must be accommodated by the bulk of the plasma.

\section{CONCLUSION}

A low-power microwave plasma source based on a microstrip split-ring resonator has been fabricated. The source can be selfstarted over a wide pressure range in air and in argon using less than $3 \mathrm{~W}$. It is capable of creating an ion density of $1.3 \times 10^{11}$ $\mathrm{cm}^{-3}$ in an argon discharge at 400 mtorr $(53.3 \mathrm{~Pa})$ while consuming only $0.5 \mathrm{~W}$. This ion density corresponds to an increase of $\sim 250 \%$ with respect to the highest ion density achieved in a microfabricated ICP under identical conditions [16].

The device is also capable of sustaining an argon discharge at atmospheric pressure while consuming $0.5 \mathrm{~W}$. Continuous operation at atmospheric pressure for $24 \mathrm{~h}$ shows no significant damage to the 9 - $\mu \mathrm{m}$-thick copper microstrips. This suggests that the plasma is not in thermal equilibrium and that the energy with which ions impact on the microstrips is low. This is in agreement with floating potential measurements, which show a very low floating voltage for pressures above 1 torr (133.3 Pa). Moreover, in that pressure range the sheaths are highly collisional and the energy with which ions arrive at the microstrip is further reduced by collisions in the sheath. Operation at lower pressure however, may require a protective coating over the microstrips to prevent possible sputtering.

Future designs will look into reducing the gap size to increase the electric field in the discharge region. By doing so, we expect to increase the pressure range at which the discharge can be self started to hundreds of torr (tens of kilopascals). Since the device requires less than $3 \mathrm{~W}$ to start and maintain the discharge, it is possible to drive the plasma source with off-the-self wireless telecommunication components. The simplicity of the fabrication process and the capability of low-power atmospheric-pressure operation make this source a good candidate for portable stand-alone systems.

\section{REFERENCES}

[1] J. C. T. Eijkel, H. Stoeri, and A. Manz, "A molecular emission detector on a chip employing a direct current microplasma," Anal. Chem., vol. 71, pp. 2600-2606, 1999.

[2] J. T. C. Eijkel, H. Stoeri, and A. Manz, "A DC microplasma on a chip employed as an optical emission detector for gas chromatography," Anal. Chem., vol. 72, pp. 2547-2552, 2000.

[3] C. G. Wilson and Y. B. Gianchandani, "Silicon micromachining using in situ DC microplasmas," J. Microelectromech. Syst., vol. 10, pp. 50-54, 2001.

[4] C. G. Wilson and Y. B. Gianchandani, "Spectral detection of metal contaminants in water using an on-chip microglow discharge," IEEE Trans. Electron Devices, vol. 49, pp. 2317-2322, Dec. 2002.

[5] R. H. Stark and K. H. Schoenbach, "Direct current glow discharge in atmospheric air," Appl. Phys. Lett., vol. 74, no. 25, pp. 3770-3772, 1999.

[6] P. Kurunczi, J. Lopez, H. Shah, and K. Becker, "Excimer formation in high-pressure microhollow cathode discharge plasmas in helium initiated by low energy electron collisions," Int. J. Mass Spectrom., vol. 205, pp. 277-283, 2001
[7] M. Miclea, K. Kunze, G. Musa, J. Franzke, and K. Niemax, "The dielectric barrier discharge-A powerful microchip plasma for diode laser spectrometry," Spectrochim. Acta B, vol. 56, pp. 37-43, 2001.

[8] A. Bass, C. Chevalier, and M. W. Blades, "A capacitively coupled microplasma $(\mathrm{CC} \mu \mathrm{P})$ formed in a channel in a quartz wafer," J. Anal. Atom. Spectrom., vol. 16, pp. 919-921, 2001.

[9] H. Yoshiki and Y. Horiike, "An atmospheric pressure microplasma source on a chip using $13.56 \mathrm{MHz}$ capacitively coupled discharge," in Proc. Inst. Electr. Eng. Jpn. Symp. Dry Process, vol. 22nd, 2000, pp. 13-18.

[10] Y. Yin, J. Messier, and J. Hopwood, "Miniaturization of inductively coupled plasma sources," IEEE Trans. Plasma Sci., vol. 27, pp. 1516-1524, Oct. 1999.

[11] A. M. Bilgic, U. Engel, E. Voges, M. Kuckelheim, and J. A. C. Broekaert, "A new low-power microwave plasma source using microstrip technology for atomic emission spectrometry," Plasma Sourc. Sci. Technol., vol. 9, no. 1, pp. 1-4, Feb. 2000.

[12] A. M. Bilgic, E. Voges, U. Engel, and J. A. C. Broekaert, "A low-power $2.45 \mathrm{GHz}$ microwave induced helium plasma source at atmospheric pressure based on microstrip technology," J. Anal. Atom. Spectrom., vol. 15 , no. 6, pp. 579-580, 2000.

[13] I. Bahl and P. Bhartia, Microwave Solid State Circuit Design. New York: Wiley, 1988, p. 18.

[14] J. S. Hong and M. J. Lancaster, Microstrip Filters for RF/Microwave Applications. New York: Wiley, 2001, ch. 4.

[15] R. K. Hoffman, Handbook of Microwave Integrated Circuits. Norwood, MA: Artec House, 1987, p. 207.

[16] F. Iza and J. Hopwood, "Influence of operating frequency and coupling coefficient on the efficiency of microfabricated inductively coupled plasma sources," Plasma Sourc. Sci. Technol., vol. 11, no. 3, pp. 229-235, Aug. 2002.

[17] M. A. Lieberman and A. J. Lichtenberg, Principle of Plasma Discharges and Materials Processing. New York: Wiley, 1994, pp. 181-183.

[18] — Principle of Plasma Discharges and Materials Processing. New York: Wiley, 1994, p. 161.

[19] — Principle of Plasma Discharges and Materials Processing. New York: Wiley, 1994, p. 80.

[20] — Principle of Plasma Discharges and Materials Processing. New York: Wiley, 1994, ch. 11.

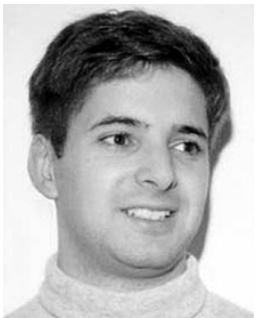

Felipe Iza (S'03) received the B.S. degree in engineering from the University of Navarra, San Sebastian, Spain, in 1997, and the M.S. degree from Northeastern University, Boston, MA, in 2001, where he is currently working toward the Ph.D. degree.

From 1997 to 1999, he was with Centro de Estudios e Investigaciones Tecnicas de Guipuzcoa (CEIT), San Sebastian, Spain. His current areas of interest include MEMS and micro-plasmas. He has researched microfabricated inductively coupled plasma sources operating at radio frequencies and is currently developing new sources to investigate submillimeter scale plasmas generated at microwave frequencies and their integration in MEMS systems.

Mr. Iza is a student member of the American Vacuum Society.

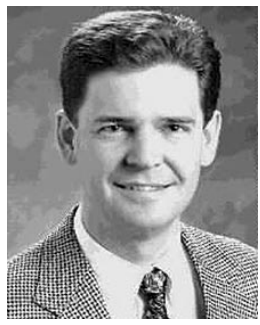

Jeffrey A. Hopwood (S'86-M'90) received the $\mathrm{Ph} . \mathrm{D}$. degree in electrical engineering from Michigan State University, East Lansing, in 1990.

He was with the T.J. Watson Research Center, the IBM Corporation, Yorktown, NY, until 1993. He is currently an Associate Professor of electrical and computer engineering with Northeastern University, Boston, MA. His research interests are focused on plasma generation and plasma processing, and include microplasma generation, micromachining of challenging materials, plasma deposition of microelectronic interconnects, and plasma-enhanced atomic layer deposition. 